\title{
Urinary copper excretion in rheumatoid arthritis
}

\author{
W. McMURRAY, V. M. MARTIN, P. SCUDDER, J. STOCKS, A. G. WHite, AND \\ T. L. DORMANDY \\ From the Departments of Chemical Pathology and Rheumatology, \\ Whittington Hospital, London
}

\begin{abstract}
McMurray, W., Martin, V. M., Scudder, P., Stocks, J., White, A. G., and Dormandy, T. L. (1975). Annals of the Rhelimatic Diseases, 34, 340-345 Urinary copper excretion in rheumatoid arthritis. The pattern of urinary copper excretion in relation to urine osmolality (as shown by series of aliquots of urine) was studied in rheumatoid patients and in control groups. Rheumatoid patients showed an abnormal copper excretion pattern compared with nonrheumatoid subjects. This was not a direct function of the raised serum copper in rheumatoid disease. Measurements based on 24-hour series of aliquots of urine (as distinct from total pooled 24-hour collections) have been shown to be a useful and sensitive method for studying copper excretion patterns.
\end{abstract}

The effectiveness of powerful chelating agents in the treatment of rheumatoid arthritis (Jaffe, 1970; Multicentre Trial Group, 1973; Day, Golding, Lee, and Butterworth, 1974; Huskisson, Wojtulewski, Berry, Scott, Hart, and Balme, 1974) points to the possible role of trace metals in this condition. That the disease is associated with raised serum copper and serum caeruloplasmin has been known for some years (Heilmeyer and Stüwe, 1938; Müller, Kluthe, and Müller, 1963; Niedermeier, 1965; Plantin and Strandberg, 1965; Lorber, Cutler, and Chang, 1968; Koskelo, Kekki, Virkkunen, Lassus, and Somer, 1966); but the mechanism, specificity, and aetiological significance of the abnormality have hardly yet been explored. One obstacle has been the difficulty of correlating serum (and synovial fluid) copper with urinary copper excretion. To the uncertainties often associated with total 24-hour urine collections, one must add, in the case of ubiquitous trace metals, the risk of contamination. Even when, with the dedicated co-operation of patient and nursing staff, such a specimen has been collected and analysed, the result may be difficult to interpret for lack of reliable normal data. To overcome this difficulty (and as part of a wider study of copper metabolism in rheumatoid arthritis) we have adopted an alternative methodological approach based on measuring urinary copper concentrations in conjunction with osmolality in 24-hour series of aliquots. The procedure is described.

\section{Materials}

(1) One-hundred and forty-six patients with rheumatoi arthritis (48 men, 98 women) have been studied. Sixty-five of the patients had received intra-articular steroid and four others systemic steroid or ACTH therapy. Eight had had treatment with gold in the past. All were on conventional analgesic/anti-inflammatory therapy. Patients on penicillamine were studied separately and are not included in the above series. (2) Forty-five normal control subjects have been investigated ( 27 men, 18 women) between the ages of nineteen and 71 years. This group excludes women on the contraceptive pill or on hormone therapy. (3) Eleven nonpregnant women have been studied as a separate group: nine were on an oestrogen-containing contraceptive pill and two were receiving oestrogen therapy for postmenopausal symptoms.

\section{Methods}

URINARY COPPER EXCRETION

\section{Urine collection}

Instead of large 24-hour urine containers the patients (and control subjects) were provided with a dozen small $(15 \mathrm{ml})$ aliquot bottles. They were asked to collect a small sample of every specimen of urine passed in the course of 24 hours. The timing and volumes were noncritical. Many such series (and repeat series) were collected by outpatients and by normal control subjects during ordinary working days.

\section{Laboratory measurements}

Copper concentration and osmolality were measured on each aliquot. The former was measured with a PerkinFlmer 306 atomic absorption spectrophotometer. The 


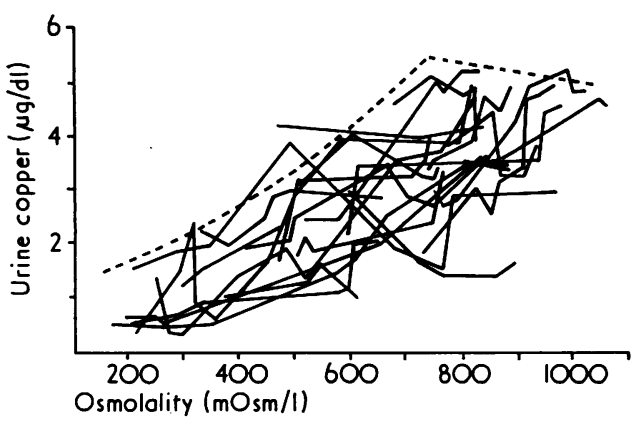

FIG. 1. Copper concentrations against osmolalities in 24-hour series of aliquots of urine from normal subjects

latter was measured cryoscopically with an Advanced osmometer (Fisons Ltd., Loughborough).

\section{Definition of normal 'area'}

The results from normal subjects (45 24-h series, a total of 320 individual aliquots) were plotted graphically. Fig. 1 shows a typical group of curves. Each point represents one aliquot, i.e. a sample of one urine specimen. Each irregular curve represents a 24-hour series of aliquots, i.e. samples of every urine specimen passed in the course of 24 hours. The curves do not represent a chronological sequence comparable to a glucose tolerance curve, but they distinguish between several 24-hour series of aliquots (i.e. several series of individual points) plotted on the same graph. When plotting a 24-hour series, the osmolality copper correspondence points of each aliquot are marked first. The points are then connected by straight lines in ascending order of copper concentration.

Limits of normal were defined by plotting the 24-hour series of urines from our 45 normal subjects. The demarcation line between normal and abnormal was deliberately drawn so as to separate two 'areas'. The normal area (to the right and below the line) enclosed over $98 \%$ of individual points (over $95 \%$ of complete 24-h curves) derived from our group of normals. It does not, in other words, represent a theoretical concept based on a preconceived relation between normal urine osmolality and normal urine copper concentration; and we have sought no mathematical or physiological explanation to account for its shape.

\section{Assessment of subsequent curves}

Subsequent 24-hour series of urine aliquots were assessed in terms of the normal and abnormal areas as defined above Curves falling within the normal area were accepted as normal. Curves with one or more points falling outside the normal area were by definition abnormal. It should be noted that in the majority of abnormal aliquots (each represented by a point outside the normal area) the copper concentrations were abnormally high only in relation to the osmolality: i.e. on the graphs the points were displaced outside the normal area to the left, not upwards.

Comparison between 24-hour series of aliquots and total 24-hour collections.

The results of 24-hour series of aliquots of urine were compared with the single copper/osmolality correspondence points derived from total pooled 24-hour collections from fourteen normal control subjects and from eighteen patients with rheumatoid arthritis.

\section{OTHER MEASUREMENTS}

Serum copper was measured by atomic absorption spectroscopy. Serum caeruloplasmin was measured by single radial immunodiffusion on M-Partigen immunodiffusion plates (Hoechst Pharmaceuticals, London).

\section{Results}

Our findings in serum and synovial fluid will be discussed in detail in a subsequent paper; but for the interpretation of different copper excretion patterns in different groups it is necessary to take into account the corresponding serum copper and serum caeruloplasmin levels, which are summarized in Table $I$.

Fig. 1 shows the osmolality-related copper excretion pattern in normal subjects, excluding women on contraceptive pills or oestrogen therapy. Figs 2 and 3 show the pattern in rheumatoid men and women, respectively. Fig. 4 shows the pattern in normal women on the contraceptive pill or on oestrogen therapy. It will be noted that, despite the high serum copper in the last group (as high as or higher than the serum copper levels in rheumatoid patients), the urinary excretion pattern was only marginally abnormal. The differences between the groups are

Table I Serum copper and serum caeruloplasmin levels in normal and rheumatoid subjects (mean $\pm S D$ )

\section{Group*}

Normal

Men (27)

Women not on oestrogen or pill (18)

Women on oestrogen or pill (11)

\section{Rheumatoid \\ Men (48) \\ Women (98)}

Serum copper $(\mu g / d l)$

$106 \cdot 8 \pm 7 \cdot 7$

$125 \cdot 5 \pm 11 \cdot 4$

$198 \cdot 8 \pm 16 \cdot 3$

$165 \cdot 8+12 \cdot 9$

$180 \cdot 7 \pm 14 \cdot 6$
Serum caerulosplamin ( $\mathrm{mg} / 100 \mathrm{ml})$

$26 \cdot 5 \pm 2 \cdot 3$

$40 \cdot 5 \pm 6 \cdot 2$

$49 \cdot 6 \pm 6 \cdot 5$

$40 \cdot 1+4 \cdot 5$

$45 \cdot 6 \pm 8 \cdot 3$

*Figures in parentheses indicate number of subjects in each group. 


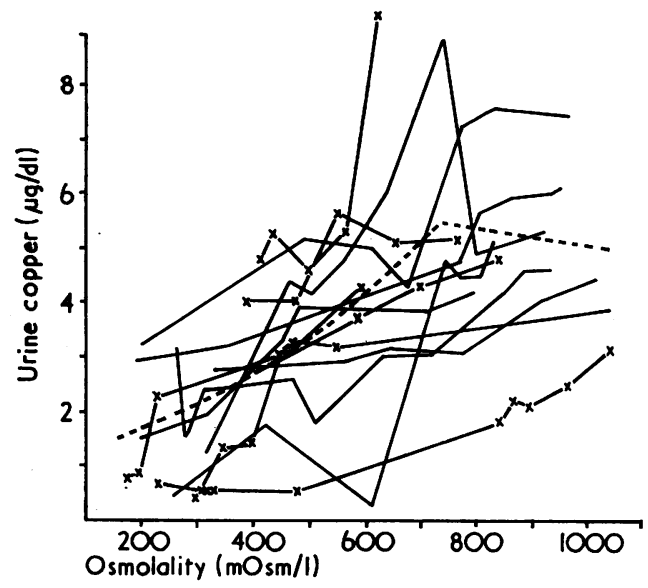

FIG. 2 Copper concentrations plotted against osmolalities in 24-hour series of aliquots of urines from male rheumatoid patients. Broken line represents limits of normal area. Solid lines represent series from patients with a normal serum copper

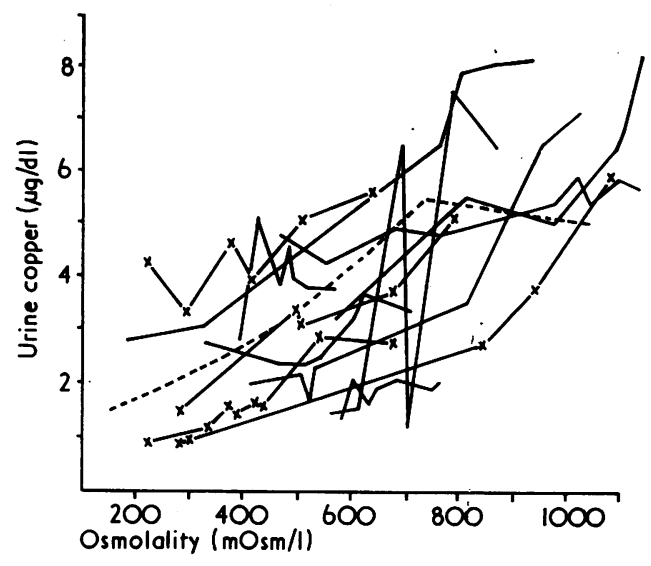

FIG. 3 Copper concentrations plotted against osmolalities in 24-hour series of aliquots of urines from female rheumatoid patients. Broken line represents limits of normal area. Solid lines represent series from patients with a normal serum copper

Table II Percentage of normal aliquots of urine in normal and in rheumatoid subjects

\begin{tabular}{|c|c|c|c|}
\hline Group & No. of subjects & No. of aliquots & $\begin{array}{l}\text { Percentage of normal } \\
\text { aliquots }\end{array}$ \\
\hline $\begin{array}{l}\text { Normal } \\
\text { Men } \\
\text { Women not on oestrogens } \\
\text { Women on oestrogens or pill }\end{array}$ & $\begin{array}{l}27 \\
18 \\
11\end{array}$ & $\begin{array}{l}171 \\
145 \\
76\end{array}$ & $\begin{array}{l}96 \\
95 \\
92\end{array}$ \\
\hline $\begin{array}{l}\text { Rheumatoid } \\
\text { Men } \\
\text { Women }\end{array}$ & $\begin{array}{l}48 \\
98\end{array}$ & $\begin{array}{l}430 \\
772\end{array}$ & $\begin{array}{l}55 \\
48\end{array}$ \\
\hline
\end{tabular}

Table III Number of abnormal aliquots of urine per 24-hour series of aliquots in normal and rheumatoid subjects. The proportion of abnormal aliquots is expressed as the \% of the total number of aliquots collected over a 24-hour period

\begin{tabular}{|c|c|c|c|c|c|c|c|c|}
\hline \multirow{2}{*}{ Group*: } & \multicolumn{8}{|c|}{ No. of abnormal aliquots per 24-h series } \\
\hline & 1 & 2 & 3 & 4 & 5 & 6 & 7 & 8 \\
\hline \multirow{2}{*}{$\begin{array}{l}\text { Normal } \\
\text { Men (27) } \\
\text { Women not on oestrogens (18) } \\
\text { Women on the pill/oestrogen therapy } \\
\text { (11) }\end{array}$} & $\begin{array}{l}11 \\
11\end{array}$ & $\begin{array}{l}\mathbf{0} \\
\mathbf{0}\end{array}$ & $\begin{array}{l}\mathbf{0} \\
\mathbf{0}\end{array}$ & $\begin{array}{l}\mathbf{0} \\
\mathbf{0}\end{array}$ & $\begin{array}{l}0 \\
0\end{array}$ & $\begin{array}{l}\mathbf{0} \\
\mathbf{0}\end{array}$ & $\begin{array}{l}\mathbf{0} \\
\mathbf{0}\end{array}$ & $\begin{array}{l}0 \\
0\end{array}$ \\
\hline & 56 & 9 & 0 & 0 & 0 & $\mathbf{0}$ & $\mathbf{0}$ & 0 \\
\hline $\begin{array}{l}\text { Rheumatoid } \\
\text { Men (48) } \\
\text { Women (98) }\end{array}$ & $\begin{array}{l}85 \\
82\end{array}$ & $\begin{array}{l}85 \\
82\end{array}$ & $\begin{array}{l}46 \\
56\end{array}$ & $\begin{array}{l}31 \\
46\end{array}$ & $\begin{array}{l}23 \\
46\end{array}$ & $\begin{array}{l}8 \\
46\end{array}$ & $\begin{array}{l}\mathbf{0} \\
27\end{array}$ & $\begin{array}{l}0 \\
27\end{array}$ \\
\hline
\end{tabular}

*Figures in parentheses indicate number of subjects in each group. 


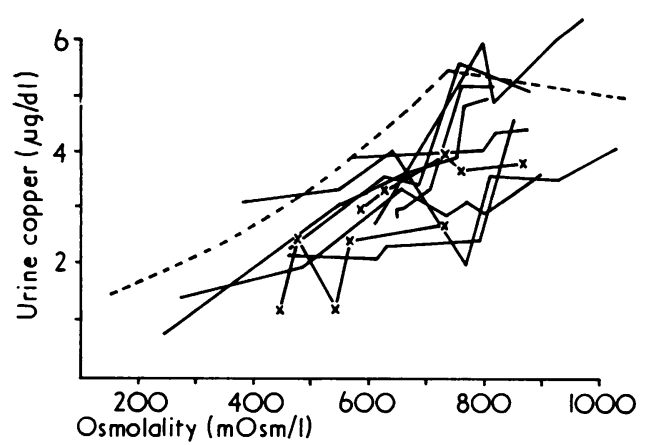

FIG. 4 Copper concentrations plotted against osmolalities in 24-hour series of aliquots of urines from nonrheumatoid women with a serum copper in the 'rheumatoid' range. Solid line $=6$ women on the contraceptive pill. $x=2$ women on post menopausal oestrogen therapy. The normal area lies below the broken line

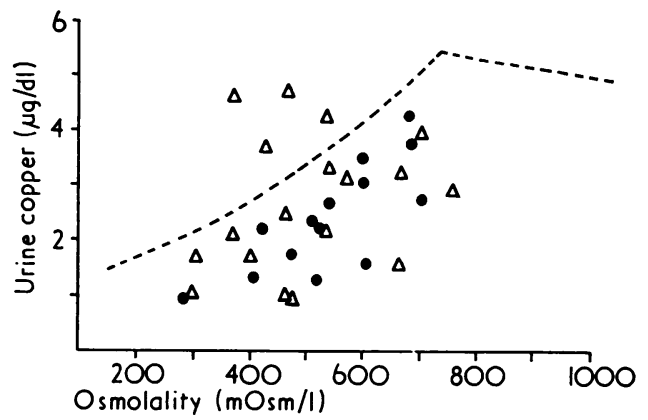

FIG. 5 Copper/osmolality relation in total pooled 24-hour urines from normal subjects $\bullet$, and from rheumatoid patients $\Delta$, related to the normal area as defined on the basis of 24-hour series of urines

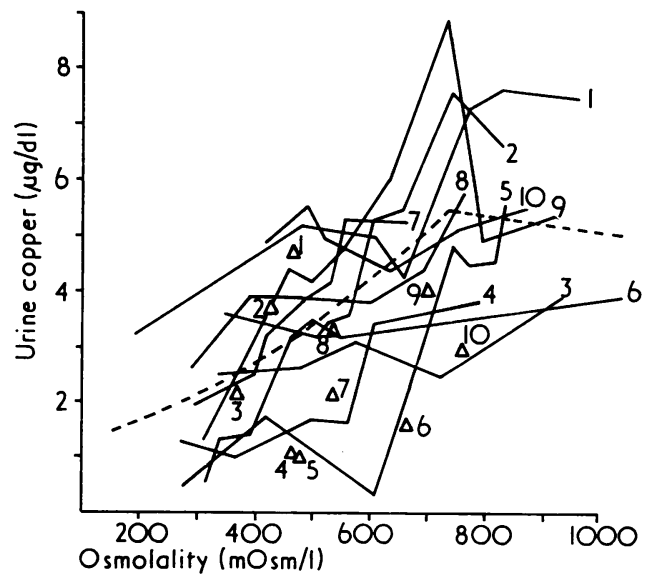

FIG. 6 Comparison between the copper/osmolality relation in total pooled 24-urines $\Delta$ and in 24-hour series of aliquots from rheumatoid patients. Numbers show the total pooled collections and series of aliquots collected from the same patients expressed quantitatively in Tables II and III. Table II shows that only about half of the total number of aliquots in rheumatoid patients gave copper/ osmolality correspondence points within the normal area. Table III gives the distribution of 24-hour series of aliquots (curves) grouped according to the number of aliquots (points) falling outside the normal area.

Comparisons between the results of 24-hour series of aliquots and of total pooled 24-hour collections from the same individuals are shown in Figs 5 and 6. In the normal controls the single copper/osmolality correspondence points representing the total pooled 24-hour collections all fell within the normal area as defined for 24-hour series (Fig. 5). In most rheumatoid patients, on the other hand, the correspondence

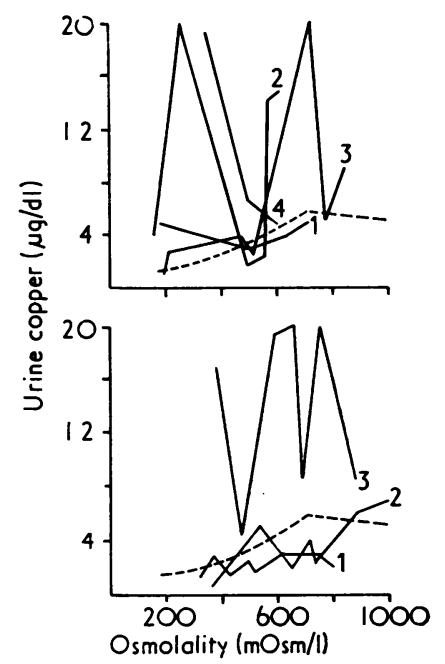

FIG. 7 Urinary copper/osmolality charts from 2 patients on D-penicillamine therapy for rheumatoid arthritis. $1=$ pretreatment; $2=$ on D-pencillamine, $300 \mathrm{mg}$ daily for 1 week; 3 and $4=$ on D-pencillamine, $1200 \mathrm{mg}$ daily for 1 month

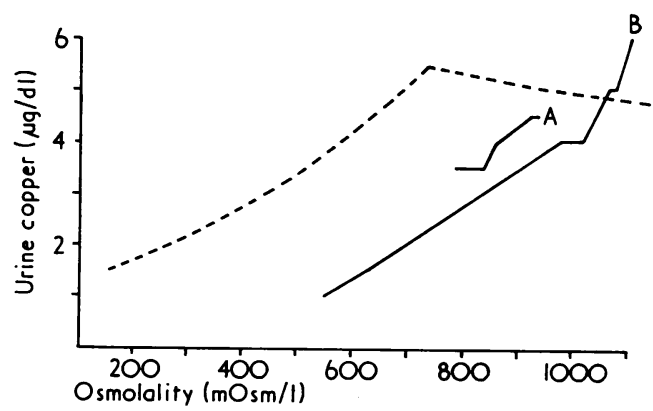

FIG. 8 Effect of $12 \mathrm{mg}$ D-penicillamine daily for 1 week on the urinary copper/osmolality chart of a normal subject. $A=$ before penicillamine; $B=$ after 1 week 'placebo" tablets (see text) 
points representing the total pooled 24-hour collections fell within the normal area but more than one of the points in the 24-hour series of aliquots fell outside (Fig. 6). It must be assumed that a few abnormal specimens passed in the course of 24 hours can become diluted by the remaining normal specimens. Since, moreover, this occurred only in rheumatoid patients, it seems reasonable to conclude that the 24-hour series of aliquots is a more sensitive index of the abnormal excretion pattern than the total pooled 24-hour collection.

The sensitivity of the 24-hour series of aliquots is further illustrated by the effect of penicillamine, a powerful copper-chelating agent. Not unexpectedly, therapeutic doses of the drug led to a grossly abnormal copper/osmolality excretion pattern (Fig. 7). However, even 'trace' concentrations of the drug, as represented by the placebo tablets of a recent doubleblind trial (12 mg daily for 7 days), had a demonstrable effect in a normal subject (Fig. 8).

\section{Discussion}

Raised serum copper levels in rheumatoid arthritis compared both to normal men and to normal women not on oral contraceptives are in agreement with the findings of other groups of workers (Plantin and Strandberg, 1965; Halsted, Hackley, and Smith, 1968). Raised serum copper levels in women on oral contraceptives or on postmenopausal oestrogen therapy were not significantly different from the levels in rheumatoid arthritis. It is therefore possible to compare the copper excretion pattern of rheumatoid patients not only with the excretion pattern of nonrheumatoid subjects with a normal serum copper but also with the excretion pattern of nonrheumatoid subjects with a serum copper in the 'rheumatoid' range. Both comparisons show an abnormal copper excretion in rheumatoid arthritis. That this is not simply a reflection of the raised copper levels is further supported by the fact that in some rheumatoid patients a normal serum copper was associated with an abnormal urinary copper excretion.

Theoretically at least three possible explanations can be envisaged. First, if copper were less firmly protein-bound in the serum of rheumatoid subjects than in normal serum more copper might be filtered by the glomeruli at any serum copper level. Although there have been suggestions in the past of an abnormal copper/caeruloplasmin ratio in rheumatoid arthritis, we have been unable to confirm this Second, since impaired glomerular function and proteinuria are relatively common in rheumatoid disease (Bulger, Healey, and Polinsky, 1968; Sørensen, 1960; Burry, 1972), the possibility must be considered that the 'excess' copper in urine depends on abnormal caeruloplasmin excretion. This explanation too is contradicted by our preliminary studies which suggest that little if any urinary copper in these patients is caeruloplasmin-bound. Third, the increased copper excretion in rheumatoid patients could reflect the presence both in serum and in urine of a copper-binding peptide. This might compete with caeruloplasmin for copper in serum and might be of sufficiently small molecular size to pass into the glomerular filtrate. There is some indirect experimental evidence to support this possibility (Gerber, 1966; Kryzmien, 1974) and it is at present being explored.

At a more general level the findings illustrate the scope of measurements based on 24-hour series of aliquots of urine. Although for purposes of comparison, a number of pooled. uncontaminated 24-hour specimens have been collected during the present study, a detailed investigation of excretion patterns based on such specimens would have been virtually impossible. Series of aliquots cannot, of course, give information about absolute amounts of copper (of any other trace metal) excreted in urine; but this. information is rarely of interest or of practical value In the normal subject urine is a relatively insignificant route of copper loss and balance studies cannot therefore be based on total urinary excretion. For assessing abnormal excretion and for monitoring the action of chelating drugs comparative studies suggest that measurements based on 24-hour series of aliquots provide a more sensitive indicator (Figs 5-7). A 24hour series of aliquots requires multiple estimations of copper and osmolality; but, once established, neither technique is excessively time-consuming. Both from the practical point of view (speed, accuracy, precision) and on theoretical grounds osmolality rather than creatinine, sodium, or any other single chemical urine constituent seems to us the reference measurement of choice (Dormandy, 1967).

We are grateful to Mr. George Rance, FIMLT, for expert N help with the figures. P.S. was supported by a research N grant of the Arthritis and Rheumatism Council. J.S. was supported by a grant from the Wellcome Trust.

\section{References}

Bulger, R. J., Healey, L. A., AND Polinsky, P. (1968) Ann. rheum. Dis., 27, 339 (Renal abnormalities in rheumatoid arthritis)

BurRY, H. C. (1972) Ann. rheum. Dis., 31, 65 (Reduced glomerular function in rheumatoid arthritis)

DAY, A. T., Golding, J. R., Lee, P. N., AND ButterworTh, A. D. (1974) Brit. med. J., 1, 180. (Penicillamine in rheumatoid disease: a long-term study) 
Dormandy, T. L. (1967) Lancet, 1, 267 (Osmometry)

GeRBer, D. A. (1966) Arthr. and Rheum., 9, 795 (Increased copper ligand reactivity in the urine of patients with rheumatoid arthritis)

Halsted, J. A., HACKLeY, B. M., AND SMITH, J. C. (1968) Lancet, 2, 278 (Plasma-zinc and copper in pregnancy and after oral contraceptives)

Heilmeyer, L., AND Stüwe, G (1958). Klin. Wehn. Schr., 17, 925 (Der Eisen-Kupferantagonismus im Blutplasma belm Infektionsgeschehen)

Huskisson, E. C., Wojtulewski, J. A., Berry, H., Scott, J., Hart, F. D., and Balme, H. W. (1974) Brit. med. J., 1,176 (Treatment of rheumatoid arthritis with fenoprofen; comparison with aspirin)

JAFFE, I. A. (1970) Arthr. and Rheum., 13, 436 (The treatment of rheumatoid arthritis and necrotising vasculitis with penicillamine)

Koskelo, P., Kekki, M., Virkkunen, M., Lassus, A., And Somer, T. (1966) Acta rheum. Scand., 12, 261 (Serum caeruloplasmin concentration in rheumatoid arthritis, ankylosing spondylitis, psoriasis and sarcoidosis)

Kryzuien, H. (1974) Gos. Prz. Post. 45, 1740 (Wystepowanie cial wiazacych jony miedzi w moczu chorych na gosciec przewlekly postepujacy)

LoRber, A., Cutler, L., AND CHANG, C. C. (1968) Arthr. and Rheum., 11, 65 (Serum copper levels in rheumatoid arthritis; relationship of elevated copper to protein alterations)

MÜLleR, W., KLUTHE, R., AND MülleR, H. (1963) Z. Rheumaforschung, 22, 1. (On the diagnosis of the activity of chronic rheumatic diseases with special reference to the quantitative determination of haptoglobins and caeruloplasmin)

Multicentre Trial Group (1973) Lancet, 1, 275 (Controlled trial of D(-) pencillamine in severe rheumatoid arthritis)

Niedermeier, W. (1965) Ann. rheum. Dis., 24, 544 (Concentration and chemical state of copper in synovial fluid and blood serum of patients with rheumatoid arthritis)

Plantin, L. O., and Strandberg, P. O. (1965) Acta rheum. scand., 11, 35 (Whole-blood concentration of copper and zinc in rheumatoid arthritis studied by activation analysis)

Sørensen, A. W. S. (1960) Acta rheum. scand., 6, 115 (Investigation of the kidney function in rheumatoid arthritis) 